\title{
Bradykinin Receptor B1 and C-Reactive Protein as Prognostic Factors for Pharyngocutaneous Fistula Development After Laryngectomy
}

\author{
Isabelle Koob ${ }^{1}$ Anja Pickhard ${ }^{1}$ (1) - Maria Buchberger ${ }^{1} \cdot$ Melanie Boxberg $^{2} \cdot$ Rudolf Reiter $^{3} \cdot$ Guido Piontek $^{1}$. \\ Ulrich Straßen ${ }^{1}$
}

Received: 10 December 2018 / Accepted: 21 May 2019 / Published online: 27 June 2019

(c) The Author(s) 2019

\begin{abstract}
Pharyngocutaneous fistulae (PCF) are one of the most common complications after laryngectomy. Predisposing risk factors have been studied, yet knowledge to determine which patients are prone to developing a fistula remains scarce. This study aims to establish prognostic parameters to identify individual patients at risk for PCF development. As PCF and inflammation seem to be interwoven, this work focuses on markers able to detect an inflammatory response. We retrospectively analyzed all patients who had undergone a laryngectomy at our clinic in the years 2007 to $2017(n=182)$. Immunohistochemical expression of bradykinin type 1 and 2 receptor and vascular endothelial growth factor receptor 2 was studied in all available tumor samples. Additionally, the clinical inflammation parameters 'body temperature', 'pain', 'c-reactive protein (CRP)', and 'leucocytes' were postoperatively tracked in all patients. The times between fistula diagnosis, therapeutic approach, and hospital discharge were recorded. We found a strong correlation between inflammation and the formation of a fistula. High bradykinin 1 receptor expression in the tumor samples correlated with postoperative PCF development. Persistently elevated CRP and leukocyte levels beyond the 6th postoperative day were also risk factors. A decreased time lapse between PCF diagnosis and surgical revision clearly correlated with a shorter hospital stay. In this study, we identified a bradykinin 1 receptor positive patient group at high risk for development of PCF. We recommend close monitoring for fistula formation in these patients to ensure timely intervention.
\end{abstract}

Keywords Vascular endothelial growth factor receptor · Bradykinin receptor · Pharyngocutaneous fistula $\cdot$ Laryngectomy . Inflammation

\section{Introduction}

Pharyngocutaneous fistula (PCF) is one of the most common early postoperative complications after total laryngectomy. The reported incidence of PCF varies widely and ranges from 2.6 to $65.5 \%$ depending on the selected patient cohort

Anja Pickhard

a.pickhard@1rz.tum.de

1 Department for Ear- Nose- and Throat, Head and Neck Surgery, University Hospital Klinikum rechts der Isar, Technical University of Munich, Ismaninger Str. 22, 81675 Munich, Germany

2 Institute of Pathology, Technical University of Munich, Trogerstraße 18, 81675 Munich, Germany

3 Department of Otolaryngology Head and Neck Surgery, Section of Phoniatrics and Pedaudiology, University of Ulm, Ulm, Germany
$[1,2]$. On average, the incidence of PCF after head and neck surgery is around $20 \%$.

PCF is caused by a disruption of the pharyngeal mucosal suture which results in a communication between the neopharynx and cervical skin. Permanent salivary leakage from the communication leads to ongoing inflammation that inhibits proper wound healing and the onset of complementary therapy. This prolongs hospitalization, increases the costs of treatment, and, most importantly, strains the patient's physical and psychological well-being [3-5].

Many studies have focused on identifying potential risk factors for PCF. Previous radiotherapy and/or chemoradiotherapy, tumor origin, and diabetes are established factors associated with PCF [6-8]. Knowledge of predisposing factors contributing to PCF formation is established, but details on reliable and timely identification of individuals developing a postoperative PCF remain insufficient. Early prediction of PCF formation would allow for prompt imaging 
diagnostics and subsequent revision surgery. Studies have indeed displayed the beneficial effect of early surgical intervention on morbidity and duration of hospitalization in PCF patients $[9,10]$.

In this study, the main goal was to trace parameters of ongoing formation of a PCF in patients after laryngectomy. As PCF and inflammation are closely linked, the focus was on indicators of an inflammatory response. Besides the known risk factors previously mentioned, rarely evaluated factors, such as clinical and morphologic inflammation indicators, were analyzed for predictive power for PCF formation. Parameters easily assessable during clinical routine were chosen to include body temperature, pain, C-reactive protein (CRP) and leucocytes.

Tissue markers capable of detecting inflammation in the tumor and its surrounding environment were also evaluated. These included bradykinin 1 receptor (B1-R), bradykinin 2 receptor (B2-R), and vascular endothelial growth factor receptor 2 (VEGF-R2). Bradykinin is part of the kinin-kallikrein family and important to the induction of an inflammatory response. It acts via inducible B1- and constitutive B2-receptors in injured tissue and may constitute a promising prognostic indicator for PCF formation. The formation of blood vessels is also necessary for the maintenance and progression of inflammation. As an important protein in vasculogenesis, VEGF-R2 was additionally evaluated as a potential prognostic indicator for PCF.

By defining reliable and early parameters of PCF-formation, we aimed to shorten the time to PCF diagnosis, expedite appropriate treatment, and reduce convalescence.

\section{Materials and Methods}

\section{Patient Cohort}

The patient cohort of this retrospective study consisted of all patients who had undergone laryngectomy (regardless of the surgery indication) at our clinic between January 2007 and January $2017(\mathrm{n}=182)$. Detailed patient characteristics are presented in Table 1.

All risk factors for PCF described in the literature and available for retrospective chart analysis were recorded (Table 1). In addition to the acknowledged risk factors, surgeons performing the laryngectomy were recorded in an anonymized manner.

Inflammation parameters were investigated with regard to their diagnostic power. In order to obtain a broad diagnostic spectrum, preoperative morphologic and postoperative clinical parameters were subject to analysis. The former comprise the protein markers B1-R and B2-R as well as VEGF$\mathrm{R} 2$. The latter include the ten-day postoperative course of temperature and pain (VAS) and 15-day postoperative survey of serum inflammation values CRP and leucocytes.

\section{Immunhistochemical Staining}

The protein marker expression was analyzed using tumor tissue sections and non-cancerous mucosa from the resection margins of all available histopathologic specimens $(n=156)$ (Table 2). Specimens without tumor were excluded from immunohistochemical analysis. Fresh $1.5 \mu \mathrm{m}$ sections from formalin-fixed and paraffin-embedded samples were transferred to glass slides, dewaxed, and rehydrated. Antigen retrieval (microwave oven heating in citrate buffered saline for B1-R and B2-R and in EDTA buffered saline for VEGFR2) was performed according to the manufacturers' recommendations. After cooling, the slides were incubated with the primary antibody (Table 3, additional files). The reaction was developed with the labeled streptavidin-biotin-alkaline phosphatase system using DAB as a reaction indicator. After counterstaining with hematoxylin, the slides were dehydrated using ascending ethanol concentrations and mounted. Tissue samples known to express the respective antigens were used as a positive control. Antibodies of irrelevant specificity with an immunoglobulin isotype identical to that of the primary antibody were used as negative controls.

The outcome of the antibody-expression was graded by the immunoreactive score displayed in Table 4 in the additional files. A graphic illustration of the respective scores is conveyed in Fig. 1, 2, 3. For B1-R and B2-R, the membranebound and cytoplasmic expression was analyzed. For VEGFR2, membrane-bound expression was distinguished from endothelial vessel expression. The latter was evaluated by means of quantitative categorization of vascular density. In order to assess vascular density, immunohistochemical tissue samples were examined through a $10 \times$ objective and the vessels visible in every field of vision (fov) were counted. Fewer than five vessels in every fov was categorized as low expression, whereas five and more vessels in at least one fov was categorized as high expression.

\section{Statistics}

Statistical analyses were conducted using IBM ${ }^{\circledR}$ SPSS ${ }^{\circledR}$ Statistics 24. Descriptive statistics were used to characterize the variables in the patient population. Continuous variables were analyzed by $t$ test or Mann-Whitney rank sum test, and categorical variables were compared using the Chi squared test or, alternatively, Fisher's exact test. A p-value of $<0.05$ indicated statistical significance.

Risk factors were analyzed by means of the Chi square or Fisher's exact test respectively.

The relative risk and its $95 \%$ confidence interval were calculated by means of the fourfold Chi squared test. 
Table 1 Overview of patient cohort

\section{Patient collective}

\section{Overview}

Average age

$\mathrm{PCF}^{\dagger} /$ no $\mathrm{PCF}^{\dagger}$

\begin{tabular}{|c|c|c|c|c|c|c|}
\hline \multirow{2}{*}{$\frac{\mathrm{TNM}}{\mathrm{T} \text {-status }}$} & \multicolumn{2}{|c|}{ TNM-Status } & \multicolumn{2}{|l|}{ Total $\left(\mathrm{n}^{\ddagger}\right)$} & PCF (\%) & \multirow{2}{*}{$\frac{\text { No PCF }(\%)}{7(87.5)}$} \\
\hline & \multicolumn{2}{|l|}{$\mathrm{T} 1$} & \multicolumn{2}{|l|}{8} & $1(12.4)$ & \\
\hline & \multicolumn{2}{|l|}{$\mathrm{T} 2$} & \multicolumn{2}{|l|}{45} & $17(37.8)$ & $28(62.2)$ \\
\hline & \multicolumn{2}{|l|}{$\mathrm{T} 3$} & \multicolumn{2}{|l|}{52} & $11(21.2)$ & $41(78.8)$ \\
\hline & \multicolumn{2}{|l|}{$\mathrm{T} 4$} & \multicolumn{2}{|l|}{69} & $15(21.7)$ & $54(78.3)$ \\
\hline & \multicolumn{2}{|l|}{ Total } & \multicolumn{2}{|l|}{174} & $44(25.3)$ & $130(74.7)$ \\
\hline \multirow[t]{5}{*}{$\mathrm{N}$-status } & \multicolumn{2}{|l|}{ No } & \multicolumn{2}{|l|}{84} & $26(31)$ & $58(69)$ \\
\hline & \multicolumn{2}{|l|}{ N1 } & \multicolumn{2}{|l|}{25} & $5(20)$ & $20(80)$ \\
\hline & \multicolumn{2}{|l|}{$\mathrm{N} 2$} & \multicolumn{2}{|l|}{63} & $13(20.6)$ & $50(79.4)$ \\
\hline & \multicolumn{2}{|l|}{ N3 } & \multicolumn{2}{|l|}{2} & $0(0)$ & $2(100)$ \\
\hline & \multicolumn{2}{|l|}{ Total } & \multicolumn{2}{|l|}{174} & $44(25.3)$ & $130(74.7)$ \\
\hline M-status & M0 & & $169(97 \%)$ & & $43(25.4)$ & $126(74.6)$ \\
\hline & M1 & & $5(3 \%)$ & & $1(20)$ & $4(80)$ \\
\hline & Total & & $174(100 \%)$ & & $44(25.3)$ & $130(74.7)$ \\
\hline Grading & G0 & & 1 & & $1(100)$ & $0(0)$ \\
\hline & G1 & & 7 & & $4(57.1)$ & $3(42.9)$ \\
\hline & $\mathrm{G} 2$ & & 97 & & $21(21.6)$ & $7678.4)$ \\
\hline & G3 & & 63 & & $16(25.4)$ & 47 (74.6) \\
\hline & Total & & 168 & & $42(25)$ & $126(75)$ \\
\hline Main tumor & & Tumour entity & & Total $\left(\mathrm{n}^{\dot{\hbar}}\right)$ & PCF (\%) & No PCF (\%) \\
\hline Hypopharynx & & SCC* & & 55 & $19(34.5)$ & $36(65.5)$ \\
\hline Larynx & & SCC* & & 111 & $23(20.7)$ & $88(79.3)$ \\
\hline Hypopharynx and Larynx & & $\mathrm{SCC}^{*}$ & 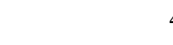 & 4 & $1(25)$ & $3(75)$ \\
\hline Thyroid gland & & Papillary & 2 & 2 & $0(0)$ & $2(100)$ \\
\hline & & Follicular & 2 & 2 & $1(50)$ & $1(50)$ \\
\hline & & Total & 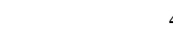 & 4 & $1(25)$ & $3(75)$ \\
\hline Synovial sarcoma & & & 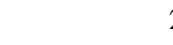 & 2 & $0(0)$ & $2(100)$ \\
\hline non tumorous entities & & Alkali burns & 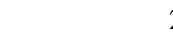 & 2 & $1(50)$ & $1(50)$ \\
\hline & & Laryngeal stenosis & & 1 & $0(0)$ & $1(100)$ \\
\hline & & Radiogenic necrosis & & 1 & $0(0)$ & $1(100)$ \\
\hline & & No specification & & 2 & $0(0)$ & $2(100)$ \\
\hline Risk factors & $\mathrm{n} \mathrm{A}$ & lysed & $\mathrm{n}^{\ddagger}$ Applicabl & & PCF (\%) & Non PCF $(\%)$ \\
\hline Alcohol & 166 & & 119 & & $31(26)$ & $88(74)$ \\
\hline Nicotine & 166 & & 119 & & $33(27.7)$ & $86(72.3)$ \\
\hline Diabetes & 167 & & 31 & & $8(25.8)$ & $23(74.2)$ \\
\hline Previous $\mathrm{RT}^{\S}$ & 182 & & 20 & & $4(20)$ & $16(80)$ \\
\hline Previous $\mathrm{RCT}^{\S}$ & 182 & & 16 & & $10(62.5)$ & $6(37.5)$ \\
\hline Pectoralis Flap & 182 & & 3 & & $1(33.3)$ & $2(66.7)$ \\
\hline Radialis Flap & 182 & & 18 & & $5(27.8)$ & $13(72.2)$ \\
\hline
\end{tabular}

${ }^{\S} R T$ radiotherapy; $R C T$ radiochemotherapy

${ }^{\dagger} P C F$ pharyngocutaneous fistula

$\$$ Number of valid cases; Percentage indication refers to number of valid cases

*squamous cell carcinoma

182 (160 male/22 female)

63 [95\% confidence interval: 62-65] $45(25 \%) / 137(75 \%)$ 
Table 2 Overview of patient cohort of the immunohistochemical analysis

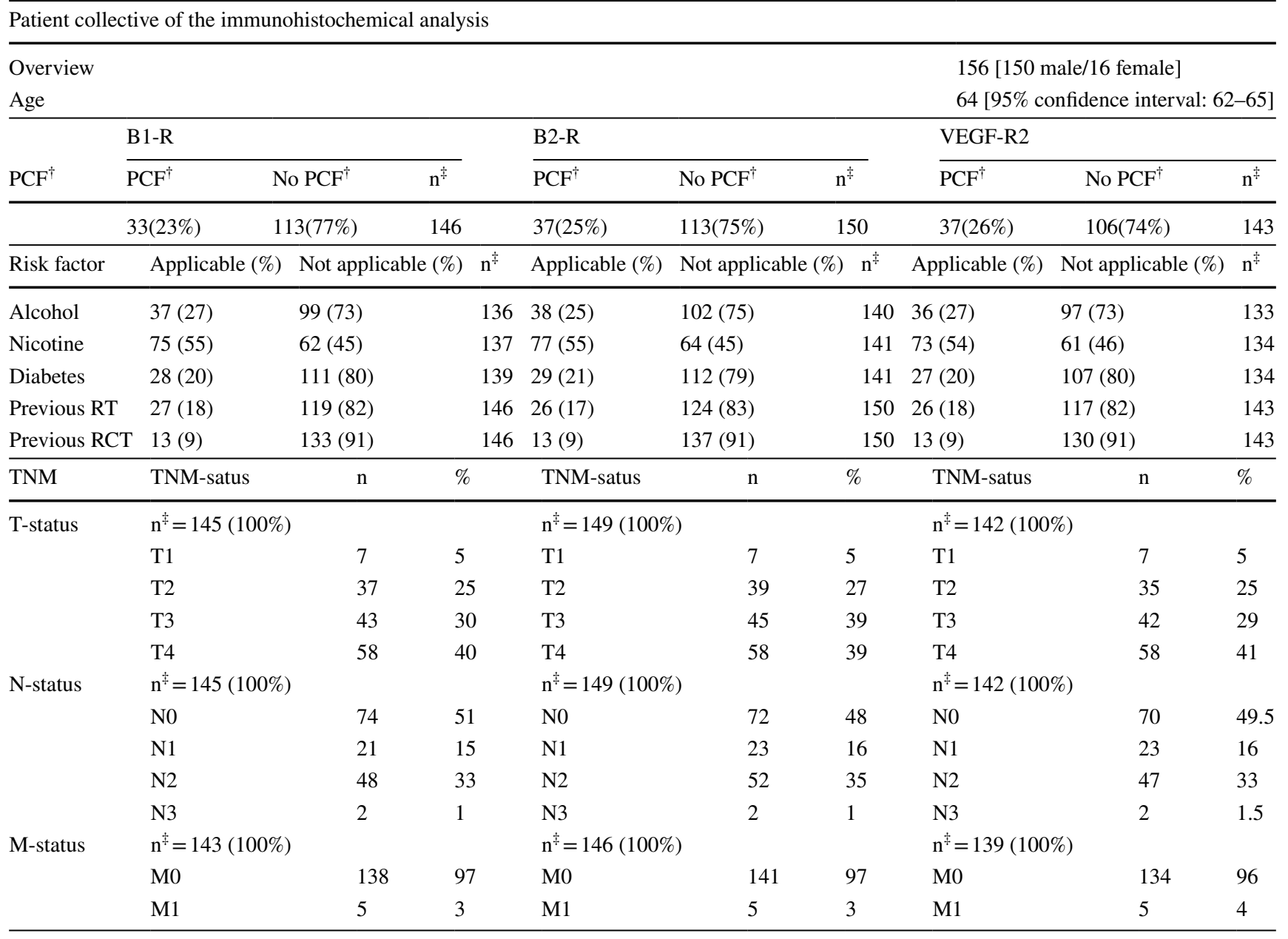

${ }^{\dagger} P C F$ pharyngocutaneous fistula

${ }^{\ddagger}$ Number of valid cases; Percentage indication refers to number of valid cases

Table 3 Additional files: Characteristics of antibodies used for immunohistochemical staining

\begin{tabular}{lll}
\hline Antibodies & Dilusion & Manufacturer \\
\hline $\begin{array}{l}\text { Rabbit Anti-Bradykinin Receptor } \\
\text { Type B1 }\end{array}$ & $1: 100$ & Thermo Fisher \\
$\begin{aligned} \text { Rabbit Anti-Bradykinin Receptor } \\
\text { Type B2 }\end{aligned}$ & $1: 100$ & Waltham. MA, USA \\
$\begin{array}{l}\text { Rabbit Anti-VEGF Receptor 2 } \\
\text { antibody }\end{array}$ & $1: 100$ & Salem. MA, USA \\
& & Abcam \\
\hline
\end{tabular}

Individual parameters showing a significant association with PCF development in the univariate model were analyzed in a logistic regression model (binary logistic regression approach using log-rank) in order to determine their power of affecting the probability of PCF formation.

Receiver operating characteristic curves and Youdenindex were used to ascertain ideal cut-off values for CRP and leucocytes.
Table 4 Additional files: Immunoreactive score

\begin{tabular}{|c|c|c|c|c|c|}
\hline \multicolumn{4}{|c|}{$\begin{array}{l}\text { Membrane-bound immunoreactive } \\
\text { score }=\mathrm{PP}^{\dagger}+\mathrm{SI}^{\ddagger}\end{array}$} & \multicolumn{2}{|c|}{ Cytoplasmatic score } \\
\hline $\mathrm{PP}^{\dagger}$ & & $\mathrm{SI}^{\ddagger}$ & & $\mathrm{SI}^{\ddagger}$ & \\
\hline negative & 0 & negative & 0 & negative & 0 \\
\hline$<10 \%$ & 1 & weakly positive & 1 & weakly positive & 1 \\
\hline $10-29 \%$ & 2 & moderately positive & 2 & strongly positive & 2 \\
\hline $30-60 \%$ & 3 & strongly positive & 3 & / & 3 \\
\hline$>60 \%$ & 4 & I & 4 & I & 4 \\
\hline
\end{tabular}

${ }^{\dagger} P P$ percentage points: percentage of stained tumor cells

${ }^{\ddagger}$ SI staining intensity

Surgeons' PCF-rate was calculated and adjusted for the date of the surgery, thus reflecting surgeons' evolution of experience. Ultimately, Pearson's correlation was computed between the amount of laryngectomies performed and surgeons' adjusted PCF-rate. 

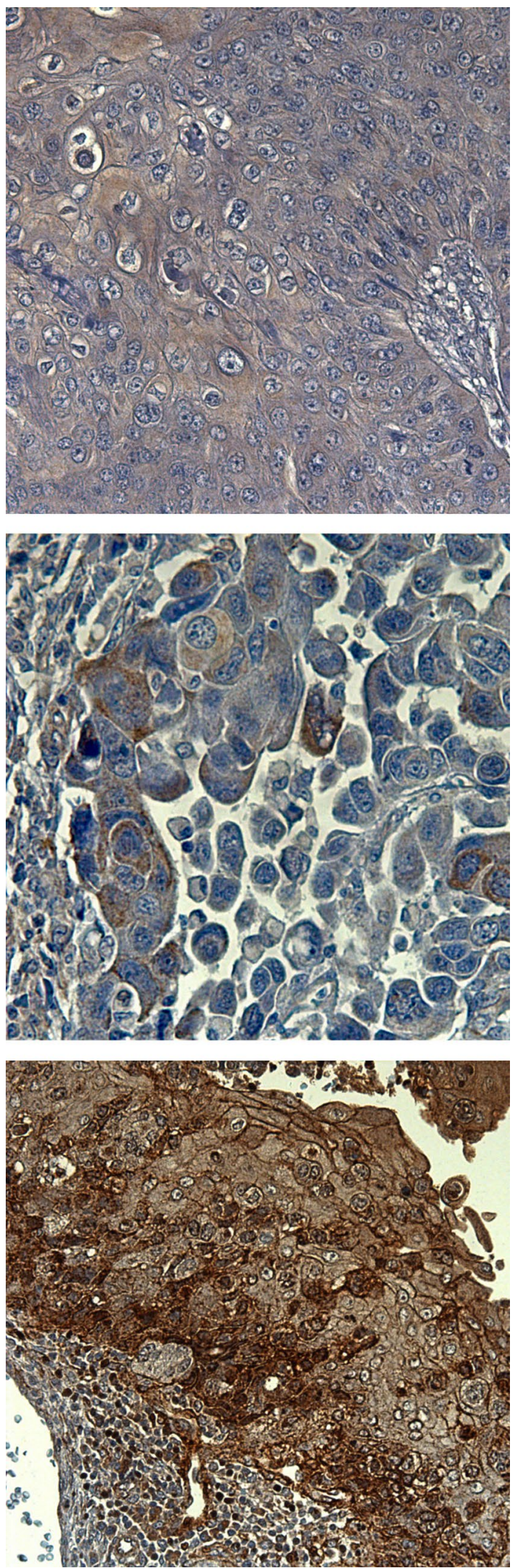

Fig. 1 Exemplary demonstration of varied immunohistochemical staining scores for B1-R. from top to bottom: B1-R immunoreactive score negative; $\mathrm{B} 1-\mathrm{R}$ immunoreactive score $=2 ; \mathrm{B} 1-\mathrm{R}$ immunoreactive score $=5$
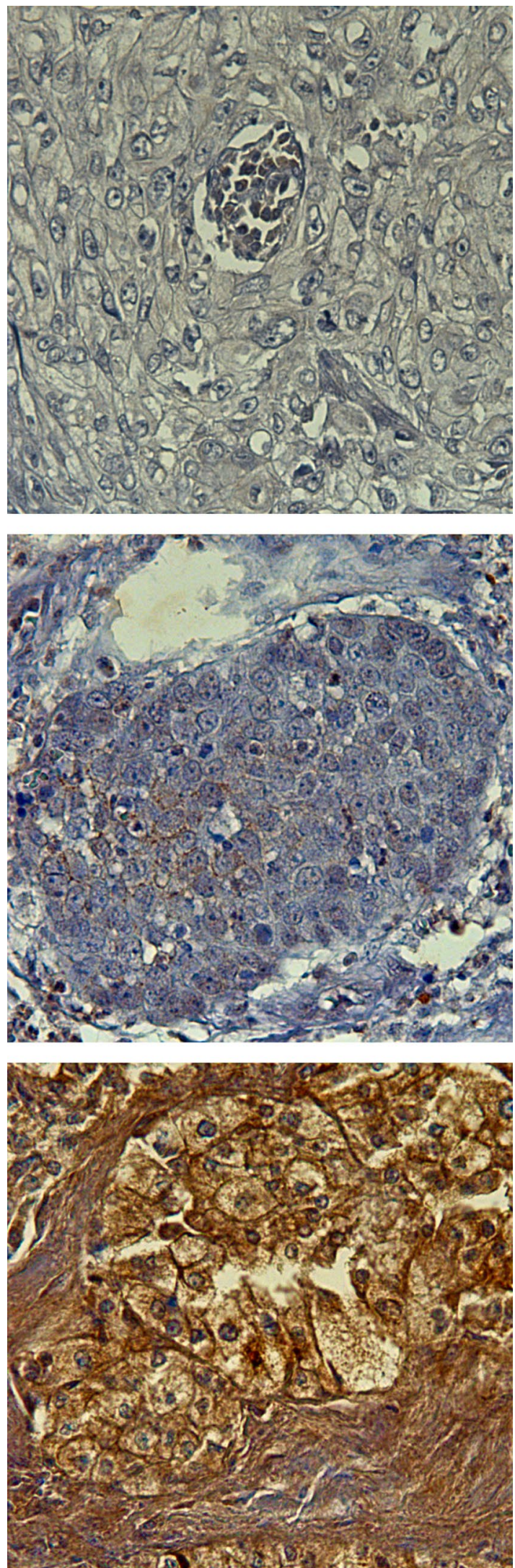

Fig. 2 Exemplary demonstration of varied immunohistochemical staining scores for B2-R. from top to bottom: B2-R immunoreactive score negative; $\mathrm{B} 2-\mathrm{R}$ immunoreactive score $=2 ; \mathrm{B} 2-\mathrm{R}$ immunoreactive score $=5$ 
Fig. 3 Exemplary demonstration of varied immunohistochemical staining scores for VEGF-R2. From top to bottom: VEGF-R2 immunoreactive score negative; VEGF-R2 immunoreactive $s c o r e=2$; VEGF-R2 immunoreactive score $=5$

\section{Results}

\section{Elevated CRP and Leukocyte rates in Blood Samples Reveal a Fistula}

The median day of PCF diagnosis was postoperative day 11 (range 3-28). Twenty-five percent $(n=45)$ of the included patients developed PCF. These patients showed a significantly $(\mathrm{p}<0.001)$ longer hospital stay after laryngectomy (mean 59 days) than patients without PCF (mean 26 days). PCF-patients also showed significantly higher average values of CRP and leucocytes during the postoperative period $\left(p_{\mathrm{CRP}}=0.024, \mathrm{p}_{\text {leucocytes }}=0.026\right)$. For the remaining clinical parameters, pain and body temperature, no significant differences were established. As CRP and leucocytes started to differ around the 6th postoperative day between PCF-patients and non-PCF-patients, cut-off values were determined for days 6-15 (Fig. 4 and Fig. 5). Optimal cut-off values were determined to be $6.1 \mathrm{mg} / \mathrm{dl}$ for CRP and $8.3 \mathrm{G} / \mathrm{l}$ for leucocytes (Fig. 6 and Fig. 7). With the set cut-off-values combined, a sensitivity of 0.43 , specificity of 0.84 , positive predictive value of 0.45 , and negative predictive value of 0.83 were achieved. If both leucocytes and CRP exceeded the cut-off values, the relative risk for fistula development was 2.63 .

\section{Previous Radiochemotherapy and Surgical Skills are Independent Predictors for PCF-Formation}

Out of the analyzed preoperative risk factors, only two proved to be of significant statistical relevance in our cohort: PCF is associated with previous radiochemotherapy and with the specific surgeon performing the laryngectomy. The logistic regression analyses confirmed that the factors 'previous radiochemotherapy' (odds ratio $=57.490$ ) and 'surgeon' (odds ratio $=14.925$ ) are independent predictors for PCFformation. A detailed overview of all the analyzed risk factors and their relative risk is presented in Table 5.

Furthermore, a strong negative correlation $(\mathrm{r}=-0.832)$ was established between the number of performed laryngectomies and surgeons' adjusted PCF-rate $(\mathrm{p}<0.001)$.

None of the clinicopathologic variables showed significant group differences in the Chi squared test.

\section{B1-R and VEGF-R2 Expression are Independent Predictors for a Postoperative PCF Formation}

Immunohistochemistry revealed that membrane-bound and cytoplasmic expression of all three morphological
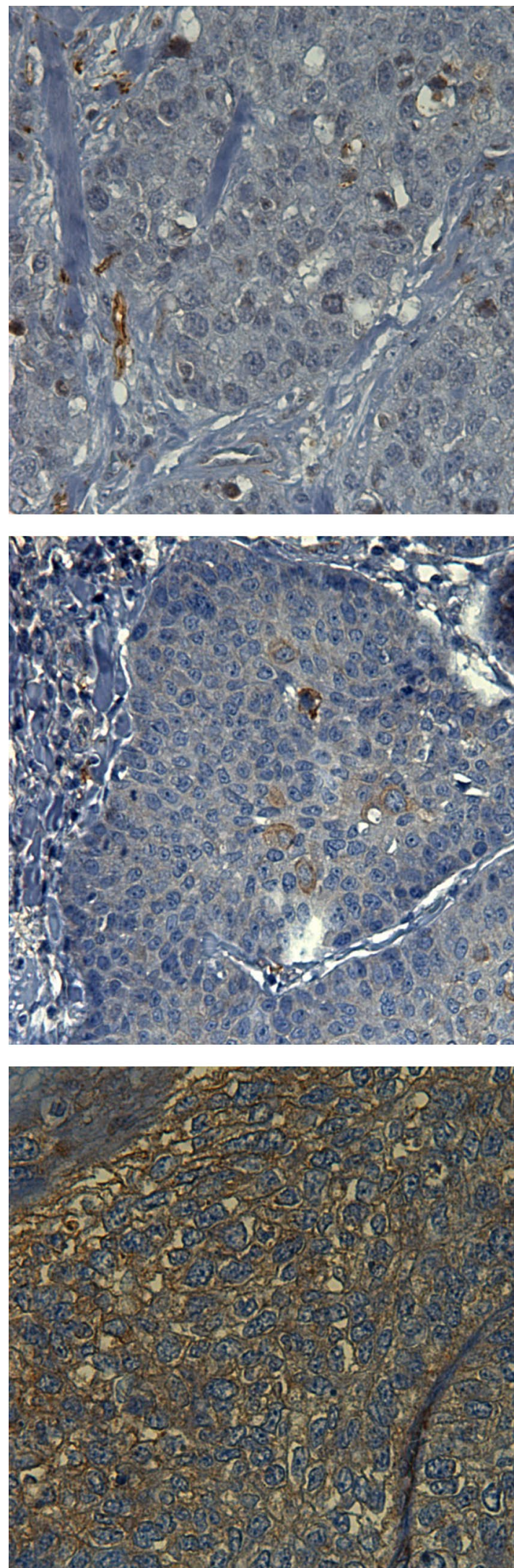
Fig. 4 Development of postoperative average CRP values in relation to the determined cut-off value of $6.1 \mathrm{mg} / \mathrm{dl}$ course of average CRP values on postoperative day 1-15

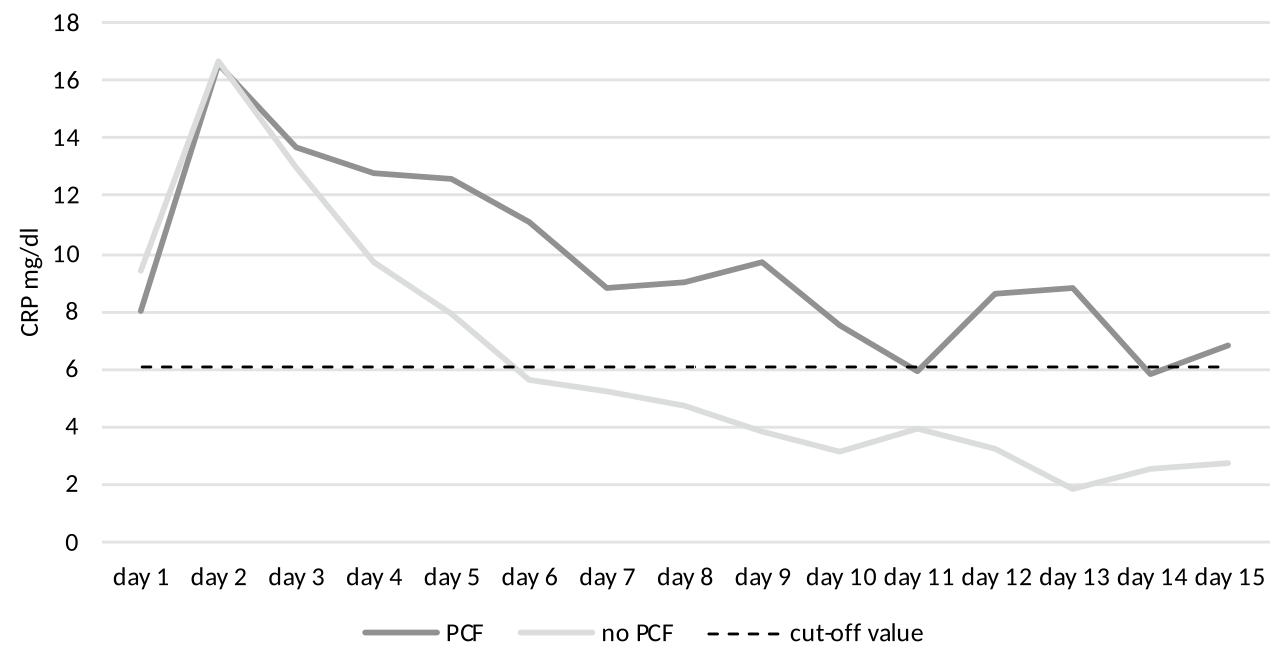

Course of average leucocyte values in postoperative day 1-15

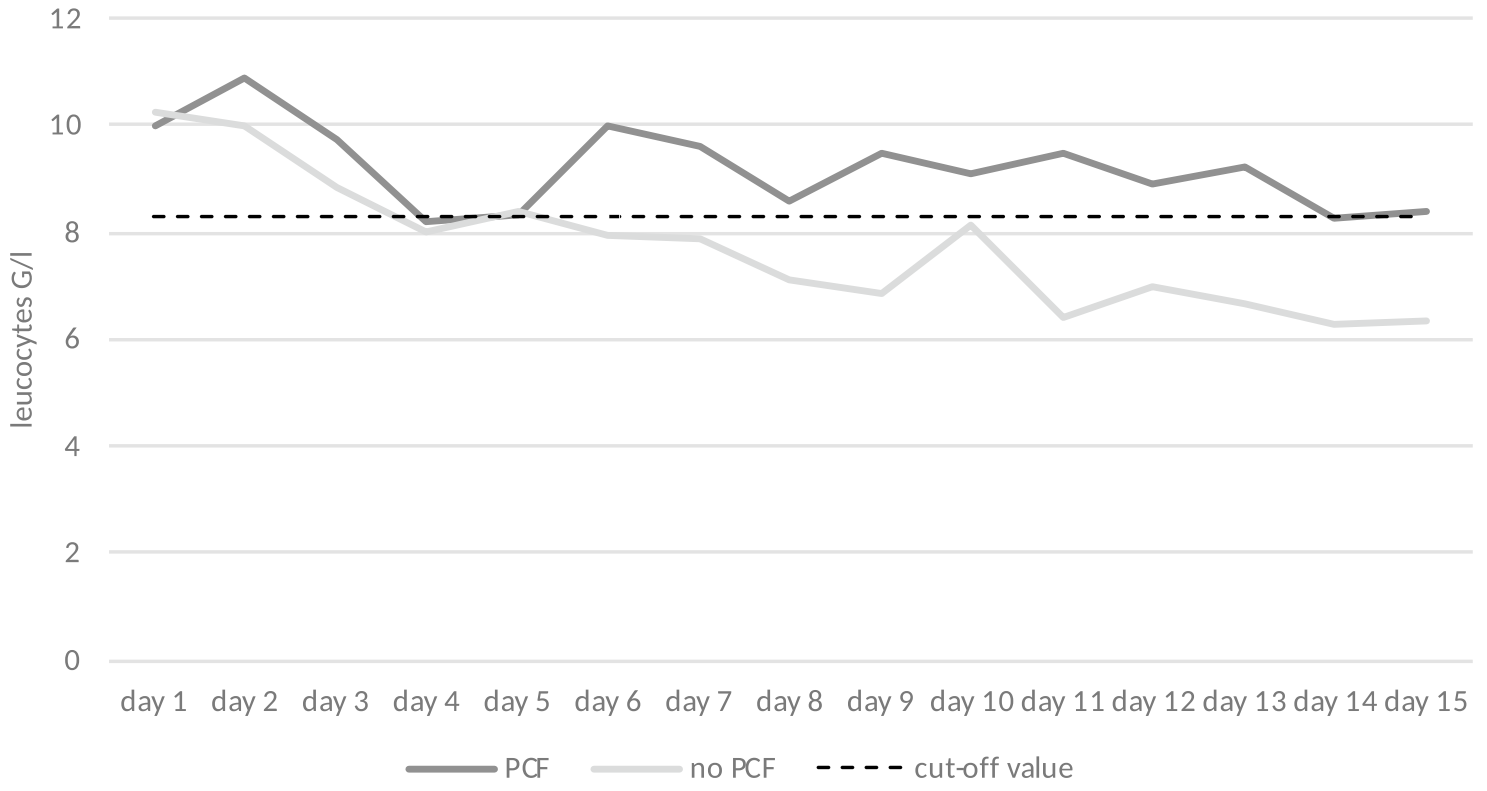

Fig. 5 Development of postoperative average leucocyte values in relation to the determined cut-off value of $8.3 \mathrm{G} / 1$

markers, B1-R, B2-R and VEGF-R2, was significantly stronger in the tumor samples as compared to the normal tissue $(\mathrm{p}<0.001)$.

VEGF-R2 high endothelial-bound expression ( $\geq 5$ vessels/field of vision) correlated with PCF development $(p=0.003)$. Also, B1-R significantly correlated with PCF formation for $\mathrm{B} 1-\mathrm{R}$ membrane-bound expression $\geq 5$ $(p=0.036)$. The relationship between the different markerscores as well as risk for PCF-formation for the respective score is displayed in Table 6.

Logistic regression analysis showed that both B1-R membrane expression $\geq 5$ and high VEGF-R2 endothelial expression were independent predictors for postoperative PCF formation with odds ratios of 12.167 and 4.812 respectively.

\section{Combined Findings of CRP $\geq 6.05 \mathrm{mg} / \mathrm{dl}$ and B1-R or VEGF-R2 Correlates with a Postoperative PCF Development}

Chi squared tests demonstrated significant correlations between PCF development and the combined finding of both a CRP-value $>6.05 \mathrm{mg} / \mathrm{dl}$ and either a B1-R score $\geq 4$ $(\mathrm{p}=0.039)$, a membrane-bound VEGF-R2 score $\geq 2$ 


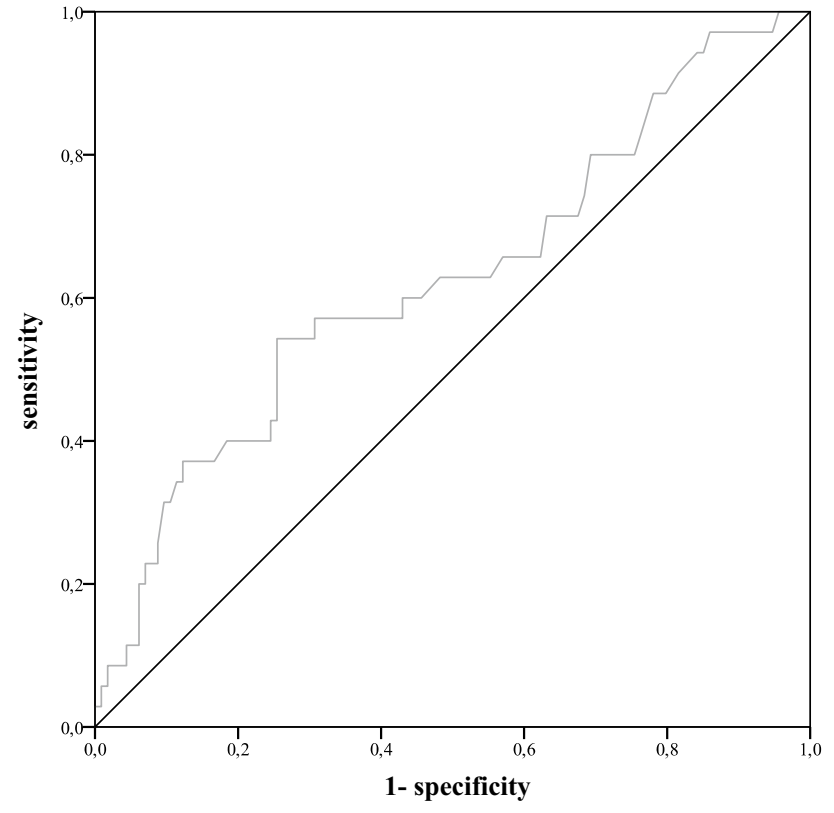

Fig. 6 ROC curve for CRP values on postoperative day 6-15

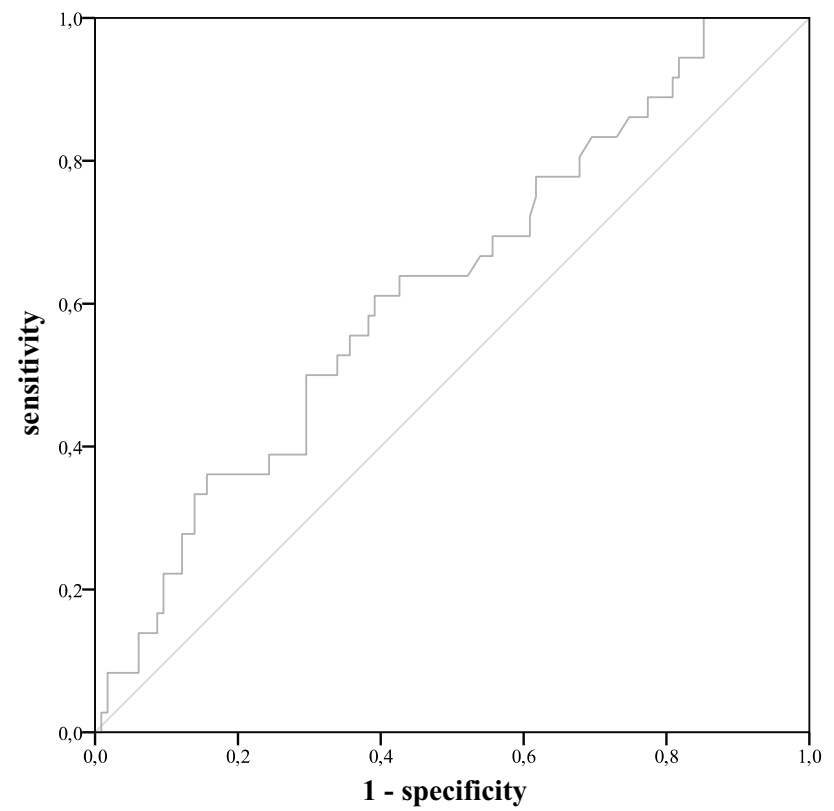

Fig. 7 ROC curve for leucocyte values on postoperative day 6-15

$(\mathrm{p}=0.033)$, or a high endothelial expression of VEGF$\mathrm{R} 2(\mathrm{p}<0.001)$. A postoperative leucocyte value $>8.3 \mathrm{G} / \mathrm{l}$ only showed a significant correlation with PCF development when combined with a high endothelial expression of VEGF-R2. In the case of a combined finding of a B1-R score $\geq 4$ and a CRP value $>6.1 \mathrm{mg} / \mathrm{dl}$, the risk to develop PCF was $100 \%$.

\section{Discussion}

PCF remains one of the most common and challenging complications after laryngectomy. A PCF may turn a short hospital stay into a prolonged ordeal complicated by complex wound care, delayed onset of voice rehabilitation and oral diet initiation, and accessory revision surgery [11]. To avoid, or at least minimize, this sequelae, it is imperative to identify high risk patients.

\section{Risk Factors}

Many studies have investigated contributing risk factors to PCF with often controversial results [8, 12-15]. Moreover, the documented preoperative risk factors can only be influenced to a very limited extent.

This study identified only two independent risk factors out of the numerous acknowledged and analyzed factors: previous radio chemotherapy $(\mathrm{p}=0.001)$ and the influence of the surgeon $(p=0.031)$. Interestingly, radiotherapy alone, though often reported as a predisposing factor for PCF formation due to tissue scarring, did not show a correlation with PCF [1, 6, 16-19]. Combined radiochemotherapy, however, seemed to significantly raise the risk for PCF development. With these results, our study is in agreement with many others that did not find an increased risk for PCF after radiotherapy alone [20-22].

The second risk factor significantly associated with PCF in our study was the surgeon performing the laryngectomy. Contrary to the risk factor 'previous radiochemotherapy', this a variable may be influenced at the time of surgery and, therefore, is of great value. The development of PCF may depend on the surgeon's technique. This includes meticulous hemostasis, especially in the time and care dedicated to the pharyngeal suture. Additionally, the impact of different suture techniques utilized by surgeons in pharyngeal closure was analyzed in several studies [22-25]. For example, interrupted sutures were shown to have a detrimental effect on PCF formation in comparison to continuous sutures [24]. The results of our study furthermore delineate that a surgeon's PCF-rate is associated with their experience. It is commonly accepted that surgical skills are honed through practice. Our results substantiate this with PCF formation decreasing with increased numbers of laryngectomies performed per surgeon.

In accordance with the literature, we also demonstrated that the insertion of a voice prosthesis during the initial procedure was not a significant risk factor for the development of PCF [19, 26-28]. 
Table 5 Evaluation of risk factors via Chi squared test (Fisher's exact test when applicable) and calculation of relative risks

\begin{tabular}{|c|c|c|c|c|}
\hline Risk factors & $\begin{array}{l}\mathrm{n}^{+} \text {total risk factor (PCF } \\
\text { and No-PCF) }\end{array}$ & $\mathrm{n}^{\ddagger}$ risk factor $\mathrm{PCF}^{\dagger}$ & Significance & $\begin{array}{l}\text { Relative } \\
\text { risk for } \\
\text { PCF }\end{array}$ \\
\hline Overview patient collecitve & $182(100 \%)$ & $45(25 \%)$ & & \\
\hline Toxicants & $\begin{array}{l}\mathrm{n}^{\ddagger} \\
\mathrm{n}^{\ddagger}\end{array}$ & $\begin{array}{l}\mathrm{n}^{\ddagger} \text { nicotine and diabetes }=44 \\
\mathrm{n}^{\ddagger} \text { alcohol }=43\end{array}$ & & \\
\hline Alcohol & $119(72 \%)$ & $31(72 \%)$ & $\mathrm{p}=0.945$ & 1.020 \\
\hline Nicotine & $119(72 \%)$ & $33(75 \%)$ & $\mathrm{p}=0.569$ & 1.185 \\
\hline Diabetes & $31(19 \%)$ & $8(20 \%)$ & $\mathrm{p}=0.857$ & 1.064 \\
\hline Main tumor & $\mathrm{n}^{\dot{+}}=174$ & $\mathrm{n}^{\ddagger}=44$ & $\mathrm{p}=1.12$ & \\
\hline Hypopharynx & $55(33 \%)$ & $19(46 \%)$ & $\mathrm{p}=0.054$ & 1.667 \\
\hline Larynx (reference) & $111(67 \%)$ & $22(54 \%)$ & & \\
\hline Hypopharynx \& larynx & $4(3.5 \%)$ & $1(4.2 \%)$ & $\mathrm{p}=1,00^{\mathrm{eF}}$ & 1.207 \\
\hline Thyroid gland & $4(3.5 \%)$ & $1(4.2 \%)$ & $\mathrm{p}=1.00^{\mathrm{eF}}$ & 1.207 \\
\hline Further entities & $8(6.7 \%)$ & $1(4.2 \%)$ & $\mathrm{p}=1.00^{\mathrm{eF}}$ & 0.603 \\
\hline TNM & $\mathrm{n}^{+}=174$ & $\mathrm{n}^{\ddagger}=44$ & & \\
\hline \multicolumn{5}{|l|}{ T-status } \\
\hline $\mathrm{T} 1$ & $9(5 \%)$ & $1(2 \%)$ & $\mathrm{p}=0.244^{\mathrm{eF}}$ & 0.294 \\
\hline T2 (reference) & $45(26 \%)$ & $17(39 \%)$ & & \\
\hline $\mathrm{T} 3$ & $51(29 \%)$ & $11(25 \%)$ & $\mathrm{p}=0.072$ & 0.560 \\
\hline $\mathrm{T} 4$ & $69(39 \%)$ & $15(34 \%)$ & $\mathrm{p}=0.062$ & 0.575 \\
\hline \multicolumn{5}{|l|}{$\mathrm{N}$-status } \\
\hline N0 (reference) & $85(49 \%)$ & $26(59 \%)$ & & \\
\hline N1 & $25(14 \%)$ & $5(11 \%)$ & $\mathrm{p}=0.301$ & 0.654 \\
\hline $\mathrm{N} 2$ & $63(36 \%)$ & $13(29 \%)$ & $\mathrm{p}=0.174$ & 0.675 \\
\hline N3 & $2(1 \%)$ & $0(0 \%)$ & $\mathrm{p}=1.000^{\mathrm{eF}}$ & \\
\hline \multicolumn{5}{|l|}{ M-status } \\
\hline M0 (reference) & $170(97 \%)$ & $43(98 \%)$ & & \\
\hline M1 & $5(3 \%)$ & $1(2 \%)$ & $\mathrm{p}=1.000^{\mathrm{eF}}$ & 0.791 \\
\hline $\mathrm{RT} \& \mathrm{RCT}^{\S}$ & $\mathrm{n}^{+}=182$ & $\mathrm{n}^{\ddagger}=45$ & & \\
\hline Previous $\mathrm{RT}^{\S}$ & $20(11 \%)$ & $4(9 \%)$ & $\mathrm{p}=0.786$ & 0.790 \\
\hline Previous $\mathrm{RCT}^{\S}$ & $16(9 \%)$ & $10(22 \%)$ & $\mathrm{p}=0.001 *$ & $2.964^{*}$ \\
\hline \multicolumn{5}{|l|}{ Surgery related risk factors } \\
\hline Voice prosthesis & $150(86 \%)$ & $34(77 \%)$ & $p=0.064$ & 0.567 \\
\hline Surgeon & & & $\mathrm{p}=0.031^{*}$ & $3.250^{*}$ \\
\hline Flap transplant & $21(12 \%)$ & $6(13 \%)$ & $p=0.664$ & 1.179 \\
\hline Radialis-flap & $18(10 \%)$ & $5(11 \%)$ & $\mathrm{p}=0.775^{\mathrm{eF}}$ & 1.147 \\
\hline Pectoralis-flap & $3(2 \%)$ & $1(2,5 \%)$ & $\mathrm{p}=0.570^{\mathrm{eF}}$ & 1.376 \\
\hline No transplant & $161(88 \%)$ & $39(87 \%)$ & & \\
\hline \multicolumn{5}{|l|}{ Preoperative parameters } \\
\hline Anaemia & $54(43 \%)$ & $15(44 \%)$ & $\mathrm{p}=0.862$ & 1.053 \\
\hline Hypothyroidism & $5(7 \%)$ & $2(12 \%)$ & $\mathrm{p}=0.330$ & 1.813 \\
\hline AST/ALT > 1 & $56(64 \%)$ & $18(75 \%)$ & $\mathrm{p}=0.201$ & 1.661 \\
\hline
\end{tabular}

Anaemia $\widehat{ }{ }^{2}$ defined as haemoglobin $<13 \mathrm{~g} / \mathrm{dl}$ for men and $<12 \mathrm{~g} / \mathrm{dl}$ for women Hypothyroidism defined as thyreoglobine stimulating hormone $>4.00 \mu \mathrm{U} / \mathrm{ml}$ *Statistically significant

${ }^{\dagger} P C F$ Pharyngocutaneous fistula

${ }^{\S} R T$ radiotherapy; $R C T$ radiochemotherapy

${ }^{\ddagger}$ Number of valid cases; Percentage indication refers to number of valid cases

eF Fisher's exact test 
Table 6 Chi squared tests (or exact Fisher's test respectively) between PCF and morphological markers as well as PCF-risk for respective score cut-off $( \pm \mathrm{CRP}>6.1 \mathrm{mg} / \mathrm{dl})$

\begin{tabular}{|c|c|c|c|c|c|}
\hline Markers & Localisation in the cell & Score & Significance & $\begin{array}{l}\text { PCF-risk for } \\
\text { markers solely }\end{array}$ & $\begin{array}{l}\text { PCF-risk for } \\
\mathrm{CRP} \geq 6.1 \mathrm{mg} / \mathrm{dl} \& \\
\text { markers }\end{array}$ \\
\hline \multirow[t]{6}{*}{ B1-R } & \multirow[t]{4}{*}{ Membrane } & $\geq 2$ & 0.906 & 0.219 & 0.375 \\
\hline & & $\geq 3$ & $0.379^{\mathrm{eF}}$ & 0.3 & 0.5 \\
\hline & & $\geq 4$ & $0.117^{\mathrm{eF}}$ & 0.444 & 1.000 \\
\hline & & $\geq 5$ & $0.036^{* \mathbf{e F}}$ & 0.75 & 1.000 \\
\hline & \multirow[t]{2}{*}{ Cytoplasm } & $\geq 1$ & 0.478 & 0.247 & 0.456 \\
\hline & & $=2$ & 0.176 & 0.333 & 0.333 \\
\hline \multirow[t]{6}{*}{ B2-R } & \multirow[t]{4}{*}{ Membrane } & $\geq 2$ & 0.112 & 0.375 & 0.6 \\
\hline & & $\geq 3$ & $1.000^{\mathrm{eF}}$ & 0.272 & 0.5 \\
\hline & & $\geq 4$ & $0.337^{\mathrm{eF}}$ & 0.000 & 0.000 \\
\hline & & $\geq 5$ & $0.572^{\mathrm{eF}}$ & 0.000 & 0.000 \\
\hline & \multirow[t]{2}{*}{ Cytoplasm } & $\geq 1$ & 0.849 & 0.258 & 0.529 \\
\hline & & $=2$ & 0.738 & 0.308 & 0.666 \\
\hline \multirow[t]{5}{*}{ VEGF-R2 } & \multirow[t]{4}{*}{ Membrane } & $\geq 2$ & 0.869 & 0.268 & 0.5 \\
\hline & & $\geq 3$ & $0.781^{\mathrm{eF}}$ & 0.211 & 0.5 \\
\hline & & $\geq 4$ & $0.339^{\mathrm{eF}}$ & 0.000 & 0.000 \\
\hline & & $\geq 5$ & $0.569^{\mathrm{eF}}$ & 0.000 & 0.000 \\
\hline & Vessels & $\geq 5 /$ fov & $0.003 *$ & 0.337 & 0.519 \\
\hline
\end{tabular}

*Statistically significant

eF Fisher's exact test

\section{Clinical Parameters}

As PCF development seems to be closely linked to inflammation, we focused on readily available clinical inflammation values. Postoperatively elevated temperature has been described as a relevant indicator for PCF in prior studies [3, $9,13,19,26]$. These results should be interpreted with caution, however, as they are mostly obtained during the early postoperative period when other causes for fever have to be taken into consideration. In our study, we could not find an association between postoperative fever and PCF formation. Nor could postoperative pain, measured by VAS, be established as an indicator for PCF development.

On the other hand, postoperative serum inflammation values (CRP and leucocytes) demonstrated promising potential as detectors for PCF formation. Previous studies on leucocytosis have been inconclusive. Schwartz et al. focused on preoperative leucocytosis, which could not be established as risk factor [16]. Mäkitie et al. found that leucocytosis on the first postoperative day predicted PCF formation [26]. It must be considered, however, that it is normal to find elevated inflammation values in the early postoperative phase due to the recent surgical trauma. In later postoperative healing stages the CRP and leucocytes should drop. In our study, persistently elevated values of CRP $>6.1 \mathrm{mg} / \mathrm{dl}$ and leucocytes $>8.3 \mathrm{G} / 1$ past postoperative day 6 indicated a maintained inflammatory response and the formation of PCF. A close postoperative tracking of CRP and leucocytes could be harnessed as a tool to identify individual patients prone to PCF development after laryngectomy. While useful as this method may be included in routine clinical practice, it should be noted that the sensitivity remains low (43\%).

\section{B1-R and VEGF-R2}

The association between PCF and serum inflammation markers indicate that fistula formation and inflammation are closely connected.

The chosen tissue markers in this study are all directly or indirectly involved in inflammatory processes. The two bradykinin-receptors, B1-R and B2-R, play a crucial role in the inflammatory reaction via pain mediation, vasodilatation, and edema, as well as smooth muscle contraction and relaxation [29-31]. A continuous tumoral inflammatory response also requires the formation of a vascular network to enable the migration of inflammatory cells. Neoangiogenesis was initially revealed through VEGF-R2 antibodies.

Overall, all the markers studied showed an over-expression in the tumor samples in contrast to normal tissue. This finding confirms an inflammatory process in cancerous tissue. Prior studies have already demonstrated the overexpression of $\mathrm{B} 1-\mathrm{R}$ in prostate carcinoma, $\mathrm{B} 2-\mathrm{R}$ in human gliomas, and VEGF-R2 in inflammatory breast cancer [32-34]. In HNSCC, however, solely B2R was identified as over-expressed [35, 36]. 
When evaluating over-expression by means of a score, it becomes clear that high scores of certain markers correlate with postoperative PCF formation. Interestingly, it is not the ubiquitously occurring B2-R that correlates with a subsequent PCF formation, but rather B1-R, whose expression is solely up-regulated in pathophysiological conditions. Also, a high vessel expression in the tumor sample, depicted by VEGF-R2, was associated with postoperative PCF development. These findings suggest that the inflammatory response is not triggered through PCF formation but that underlying inflammation present in the operating tumor field might favor postoperative PCF formation.

Furthermore, the morphological markers B1-R and VEGF-R2 appear to be closely linked to CRP $>6.1 \mathrm{mg} / \mathrm{dl}$ past the 6th postoperative day, with a significant association in the Chi squared test. Positive testing of both $\mathrm{B} 1-\mathrm{R} \geq 4$ and CRP $>6.1 \mathrm{mg} / \mathrm{dl}$ in a patient yields a PCF-rate of $100 \%$.

\section{Management}

PCF requires an encompassing management from prevention to treatment. An accurate preoperative assessment of risk factors, perioperative diligence, and postoperative vigilance for impending complications are essential. In the postoperative period, an early recognition of PCF formation is crucial in order to prevent secondary wound complications. Indeed, primary closure, not to mention conservative management, becomes problematic if the diagnosis is delayed. The chronic inflammation and supplementary infection leads to poor vascular conditions and, finally, necrosis. It is estimated that an early diagnosis and subsequent adequate treatment are essential to a successful recovery process in postoperative management of PCF $[9,11,37]$. The extent of a surgical revision depends on the fistula's dimension and contamination.

The findings of our study suggest an algorithm to facilitate early PCF diagnosis and hence a prompt surgical intervention: Preoperatively, high risk patients should be identified by screening for existing risk factors as well as for the expression of a B1-R membrane-bound score $\geq 5$ or a VEGF-R2 endothelial expression $\geq 5$ vessels/fov in the tumor samples. For selected high risk patients, a prophylactic flap-reinforced closure during laryngectomy should be taken into consideration in order to minimize the odds for a later PCF development [37-40]. Postoperatively, CRP and leucocytes should be closely tracked in every patient but with special attention in high risk patients. Any elevation of CRP and leucocytes above the set cut-off values beyond postoperative day 6 should, with regard to the specificity (84\%) of the test, be followed by prompt imaging diagnostics in order to exclude or confirm a PCF. A newly developed fistula should be treated by surgical intervention in a timely manner to decrease the patient's length of hospitalization.
To our knowledge, we are the first to propose a diagnostic algorithm based on the expression of inflammatory parameters. Such a diagnostic tool could be of great value in both reducing the financial costs of PCF and, most importantly, assisting the patient's physiological and psychological recovery.

Due to the retrospective nature of this current study, however, it is recommended that this algorithm be further supported by way of prospective research.

\section{Conclusions}

Patients showing a B1-R membrane-bound score $\geq 5$ or a VEGF-R2 endothelial score $\geq 5$ vessel/fov should be categorized as high-risk patients for PCF development. Furthermore, a postoperative elevation of CRP $\geq 6.1 \mathrm{mg} / \mathrm{dl}$ or leucocytes $\geq 8.3 \mathrm{G} / 1$ beyond the 6 th postoperative day, especially in high-risk patients, should be followed by immediate imaging diagnostics and surgical intervention. These measures will aid to avoid disease progression and thereby shorten the length of hospitalization.

Acknowledgment We thank Armin Ott from the Institute for Medical Statistics and Epidemiology, University Hospital Klinikum rechts der Isar, Technical University of Munich, for reviewing and discussing our statistical evaluation. Also, the authors thank Peter Strzelczyk for perfect technical assistance.

\section{Compliance with Ethical Standards}

Conflict of interest The authors declare no conflicts of interest.

Research Involving Human and Animal Participants This article does not contain any studies with animals or involving human participants performed by any of the authors.

Open Access This article is distributed under the terms of the Creative Commons Attribution 4.0 International License (http://creativeco mmons.org/licenses/by/4.0/), which permits unrestricted use, distribution, and reproduction in any medium, provided you give appropriate credit to the original author(s) and the source, provide a link to the Creative Commons license, and indicate if changes were made.

\section{References}

1. Paydarfar JA, Birkmeyer NJ. Complications in head and neck surgery: a meta-analysis of postlaryngectomy pharyngocutaneous fistula. Arch Otolaryngol Head Neck Surg. 2006;132:67-72.

2. Erdag MA, Arslanoglu S, Onal K, Songu M, Tuylu AO. Pharyngocutaneous fistula following total laryngectomy: multivariate analysis of risk factors. Eur Arch Otorhinolaryngol. 2013;270:173-9.

3. Esteban F, Delgado-Rodriguez M, Mochon A, Solano J, Soldado L. Solanellas J [Study of in-patient hospital stay following total 
laryngectomy: multivariable retrospective analysis of a 442 total laryngectomies]. Acta Otorrinolaringol Esp. 2006;57:176-82.

4. Timmermans AJ, Lansaat L, Kroon GV, Hamming-Vrieze O, Hilgers FJ, van den Brekel MW. Early oral intake after total laryngectomy does not increase pharyngocutaneous fistulization. Eur Arch Otorhinolaryngol. 2014;271:353-8.

5. Dedhia RC, Smith KJ, Weissfeld JL, et al. Cost-identification analysis of total laryngectomy: an itemized approach to hospital costs. Otolaryngol Head Neck Surg. 2011;144:220-4.

6. White HN, Golden B, Sweeny L, Carroll WR, Magnuson JS, Rosenthal EL. Assessment and incidence of salivary leak following laryngectomy. Laryngoscope. 2012;122:1796-9.

7. Qureshi SS, Chaturvedi P, Pai PS, et al. A prospective study of pharyngocutaneous fistulas following total laryngectomy. J Cancer Res Ther. 2005;1:51-6.

8. De Zinis LOR, Ferrari L, Tomenzoli D, Premoli G, Parrinello G, Nicolai P. Postlaryngectomy pharyngocutaneous fistula: incidence, predisposing factors, and therapy. Head Neck. 1999;21:131-8.

9. Friedman M, Venkatesan TK, Yakovlev A, Lim JW, Tanyeri HM, Caldarelli DD. Early detection and treatment of postoperative pharyngocutaneous fistula. Otolaryngol Head Neck Surg. 1999;121:378-80.

10. Iteld L, Yu P. Pharyngocutaneous fistula repair after radiotherapy and salvage total laryngectomy. J Reconstr Microsurg. 2007;23(06):339-46.

11. Kiong KL, Tan NC, Skanthakumar T, et al. Salivary fistula: blue dye testing as part of an algorithm for early diagnosis. Laryngoscope Investig Otolaryngol. 2017;2:363-8.

12. Dedivitis RA, Aires FT, Cernea CR, Brandao LG. Pharyngocutaneous fistula after total laryngectomy: systematic review of risk factors. Head Neck. 2015;37:1691-7.

13. Makitie AA, Irish J, Gullane PJ. Pharyngocutaneous fistula. Curr Opin Otolaryngol Head Neck Surg. 2003;11:78-84.

14. Ikiz AO, Uca M, Guneri EA, Erdag TK, Sutay S. Pharyngocutaneous fistula and total laryngectomy: possible predisposing factors, with emphasis on pharyngeal myotomy. J Laryngol Otol. 2000;114:768-71.

15. Virtaniemi JA, Kumpulainen EJ, Hirvikoski PP, Johansson RT, Kosma VM. The incidence and etiology of postlaryngectomy pharyngocutaneous fistulae. Head Neck. 2001;23:29-33.

16. Schwartz SR, Yueh B, Maynard C, Daley J, Henderson W, Khuri SF. Predictors of wound complications after laryngectomy: a study of over 2000 patients. Otolaryngol Head Neck Surg. 2004;131:61-8.

17. Busoni M, Deganello A, Gallo O. Pharyngocutaneous fistula following total laryngectomy: analysis of risk factors, prognosis and treatment modalities. Acta Otorhinolaryngol Ital. 2015;35:400-5.

18. Dirven R, Swinson BD, Gao K, Clark JR. The assessment of pharyngocutaneous fistula rate in patients treated primarily with definitive radiotherapy followed by salvage surgery of the larynx and hypopharynx. Laryngoscope. 2009;119:1691-5.

19. Boscolo-Rizzo P, De Cillis G, Marchiori C, Carpene S, Da Mosto MC. Multivariate analysis of risk factors for pharyngocutaneous fistula after total laryngectomy. Eur Arch Otorhinolaryngol. 2008;265:929-36.

20. Do SB, Chung CH, Chang YJ, Kim BJ, Rho YS. Risk factors of and treatments for pharyngocutaneous fistula occurring after oropharynx and hypopharynx reconstruction. Arch Plast Surg. 2017:44:530-8.

21. Saydam L, Kalcioglu T, Kizilay A. Early oral feeding following total laryngectomy. Am J Otolaryngol. 2002;23:277-81.

22. Soylu L, Kiroglu M, Aydogan B, et al. Pharyngocutaneous fistula following laryngectomy. Head Neck. 1998;20:22-5.

23. Akduman D, Naiboglu B, Uslu C, et al. [Pharyngocutaneous fistula after total laryngectomy: incidence, predisposing factors, and treatment]. Kulak Burun Bogaz Ihtis Derg. 2008;18:349-54.
24. Deniz M, Ciftci Z, Gultekin E. Pharyngoesophageal suturing technique may decrease the incidence of pharyngocutaneous fistula following total laryngectomy. Surg Res Pract. 2015;2015:363640.

25. Benson EM, Hirata RM, Thompson CB, et al. Pharyngocutaneous fistula after total laryngectomy: a single-institution experience, 2001-2012. Am J Otolaryngol. 2015;36:24-31.

26. Makitie AA, Niemensivu R, Hero M, et al. Pharyngocutaneous fistula following total laryngectomy: a single institution's 10-year experience. Eur Arch Otorhinolaryngol. 2006;263:1127-30.

27. Markou KD, Vlachtsis KC, Nikolaou AC, Petridis DG, Kouloulas AI, Daniilidis IC. Incidence and predisposing factors of pharyngocutaneous fistula formation after total laryngectomy. Is there a relationship with tumor recurrence? Eur Arch Otorhinolaryngol. 2004;261(2):61-7.

28. Parikh SR, Irish JC, Curran AJ, Gullane PJ, Brown DH, Rotstein LE. Pharyngocutaneous fistulae in laryngectomy patients: the Toronto Hospital experience. J Otolaryngol. 1998;27:136-40.

29. Stewart JM. Bradykinin antagonists: development and applications. Biopolymers. 1995;37:143-55.

30. Regoli D, Nsa Allogho S, Rizzi A, Gobeil FJ. Bradykinin receptors and their antagonists. Eur J Pharmacol. 1998;348:1-10.

31. Marceau F, Regoli D. Bradykinin receptor ligands: therapeutic perspectives. Nat Rev Drug Discov. 2004;3:845-52.

32. Taub JS, Guo R, Leeb-Lundberg LM, Madden JF, Daaka Y. Bradykinin receptor subtype 1 expression and function in prostate cancer. Cancer Res. 2003;63:2037-41.

33. Zhao Y, Xue Y, Liu Y, et al. Study of correlation between expression of bradykinin $\mathrm{B} 2$ receptor and pathological grade in human gliomas. Br J Neurosurg. 2005;19:322-6.

34. Arias-Pulido H, Chaher N, Gong Y, Qualls C, Vargas J, Royce M. Tumor stromal vascular endothelial growth factor $\mathrm{A}$ is predictive of poor outcome in inflammatory breast cancer. BMC Cancer. 2012;12:298.

35. Zhang W, Bhola N, Kalyankrishna S, et al. Kinin b2 receptor mediates induction of cyclooxygenase- 2 and is overexpressed in head and neck squamous cell carcinomas. Mol Cancer Res. 2008;6:1946-56.

36. Beck C, Piontek G, Haug A, et al. The kallikrein-kinin-system in head and neck squamous cell carcinoma (HNSCC) and its role in tumour survival, invasion, migration and response to radiotherapy. Oral Oncol. 2012;48:1208-19.

37. Patel UA, Moore BA, Wax M, et al. Impact of pharyngeal closure technique on fistula after salvage laryngectomy. JAMA Otolaryngol Head Neck Surg. 2013;139:1156-62.

38. Anschutz L, Nisa L, Elicin O, Bojaxhiu B, Caversaccio M, Giger R. Pectoralis major myofascial interposition flap prevents postoperative pharyngocutaneous fistula in salvage total laryngectomy. Eur Arch Otorhinolaryngol. 2016;273:3943-9.

39. Sayles M, Grant DG. Preventing pharyngo-cutaneous fistula in total laryngectomy: a systematic review and meta-analysis. Laryngoscope. 2014;124:1150-63.

40. Sousa AA, Castro SM, Porcaro-Salles JM, et al. The usefulness of a pectoralis major myocutaneous flap in preventing salivary fistulae after salvage total laryngectomy. Braz J Otorhinolaryngol. 2012;78:103-7.

Publisher's Note Springer Nature remains neutral with regard to jurisdictional claims in published maps and institutional affiliations. 